$166+27$ (appendix) pp., $6+4$ (appendix) figs., $41+17$ (appendix) tables, appendices, 93 refs. Dutch, English summary.

Available as paper copy (order R008P, $f 30$ including postage) or microfiches (order R008M, f 17,50, including postage) at: NARD, clo Pudoc, P.O. Box 4, 6700 AA Wageningen, Netherlands (telex 45015 blhwg $n l$ ).

\title{
An ideotype of forage maize for north-west Europe
}

P. C. Struik (Department of Field Crops and Grassland Science, Agricultural University, Haarweg 333, 6709 RZ Wageningen, Netherlands)

Accepted: 18 May 1984

\begin{abstract}
Morphological and physiological characteristics of an ideal genotype of forage maize for north-west Europe are described. This ideotype shows an optimum yield of digestible organic matter, is easy to harvest and to preserve, allows a high intake and is efficiently utilized by the ruminant.

Key-words: forage maize, ideotype, genotype, yield, digestibility, dry-matter content, intake, cell wall.

Introduction. An ideotype can be defined as the ideal genotype of a crop, in which the characteristics that maximize productivity and quality under the prevailing conditions and recommended cultural practice are combined. This implies that the ideotype should be realistic and will only be applicable for a defined environment, in this case for the climate and cultivation practices of north-west Europe. The ideotype of forage maize should:

- yield a maximum and stable amount of digestible organic matter

- be easy to harvest and to preserve

- be palatable, nutritious and allow a high dry-matter intake

- be efficiently utilized by the animal.
\end{abstract}

These demands can be translated into some model characteristics, which will be discussed in this paper.

\section{Model characteristics of forage maize in north-west Europe}

High dry-matter yield. Early vigour and cold tolerance are essential. The slow early development requires plant density to be high. Therefore this ideotype must also be a weak intraspecific competitor. To minimize mutual shading during later stages of development, the ideotype must show a prostrate leaf orientation especially of the 
long mid-leaves, a more pronounced oblong leaf shape, and a small tassel. Adverse effects of mutual shading on ear development can be minimized by using densitytolerant genotypes.

The leaf area should have an optimum efficiency. This includes, for example, maximum rate of photosynthesis, longevity with maintenance of a high activity and resistance to frost. The ideotype must also be as late maturing as possible, in order to achieve a large leaf area, prolonged presence of young leaves in the top of the canopy and delayed emergence of the (light-intercepting) tassel, so long as ear filling is still assured.

Low susceptibility to pests and diseases. Few important pests and diseases, such as ear, stalk and root rots, common smut and frit fly, are adapted to the cool weather conditions in north-west Europe. Lateness, longevity of leaves, a balanced sinksource ratio and prolonged maintenance of photosynthetic activity and genotypic resistance reduce the susceptibility to Fusarium. High levels of smut infection are rare in north-west Europe and genotypic differences in susceptibility are large. Genotypes with great early vigour might be less sensitive to frit-fly damage.

Stocky stem and superior root system. Resistance to lodging is affected by traits of the stem (e.g. height, thickness, crushing strength), root system (e.g. number, clump weight), leaves (e.g. rigidity, angle), ear (height, weight) and by general characteristics (cell-wall digestibility, vigour, earliness, susceptibiblity to pathogens). Stem diameter is interesting, since it is easy to assess and it correlates positively with lodging resistance, yield, early vigour and intake. However, it correlates negatively with digestibility and dry-matter content. A stocky stem with a high pith: rind ratio and a strong pith benefits intake, yield and lodging resistance and minimizes the adverse effects of thick stems. Selecting for a superior root system might reduce whole-plant yield. Yet it seems worth paying attention to root-lodging tolerance.

Optimum composition of cellular contents. Forage maize is deficient in mineral elements, (precursors of) vitamins, and protein. Genetic variation is small or cannot be explored without reducing yield. These deficiencies can easily be solved by giving supplements to the animal. Improving the quality of protein by introduction of mutant strains (e.g. opaque-2) reduces the crop's agronomic value and has no nutritional advantage for ruminants. High contents of non-structural carbohydrates increase intake and the efficiency of utilization, but reduce cell-wall digestibility, especially at high levels of intake. The composition of cellular contents is also important for changes occurring during ensiling but should be of minor importance as a breeding objective.

Low amount of cell-wall constituents. The amount of - poorly digestible - cell wall must be reduced without limiting lodging resistance or the size of the leaf apparatus. The ideotype should thus show a limited number of short phytomers, a high leaf: stem ratio, a slow decrease in the rate of photosynthesis after each individual leaf has fully expanded, and a large ear.

High potential cell-wall digestibility and a fast rate of cell-wall digestion. In contrast to other quality characteristics, selection for rate and extent of cell-wall digestion is possible without strongly affecting yield, although it might reduce lodging resis- 
tance. Selecting for improved cell-wall digestibility is easier than for increased organic-matter digestibility and can be done by analysing any plant part at any stage of development, provided all genotypes are sampled at the same time.

Sufficiently high dry-matter content, especially in the stover. The dry-matter content (dm \%) affects the suitability for ensiling, the concentration of nutrients in the fresh matter and the dry-matter intake. The optimum is $30-35 \%$; $\mathrm{dm} \%$ and proportion of stover are especially important. Thus the rate of senescence of stover tissue should not be too slow and the duration of the vegetative period must be limited.

A certain proportion of ear in the dry matter. Ear formation and grain filling affect crop-growth rate, longevity of leaves, capacity to store photosynthates, digestibility, production of poorly digestible cell wall, $\mathrm{dm} \%$, fermentation processes in the silo, seepage losses, intake, feed efficiency, and susceptibility to Fusarium. The ideotype should therefore have an early silking date, a large ear and a slow rate of grain filling.

Moderate level of water-soluble carbohydrates (wsc) in the stover. The conversion of wsc of the stover to starch in the grains limits losses during preservation (seepage, gaseous losses, losses after exposure to air) and boosts intake, protein utilization and digestibility of the silage. This conversion is favourable as long as it does not reduce the late-season vigour of the crop and as long as enough substrate is available for microbes during fermentation. A wsc content of $5 \%$ on the basis of the dry matter of the stover might be sufficient.

Concluding remark. These qualifications are so diverse and often contradictory that it is impossible to combine them in one genotype. The search for an ideotype is therefore the search for the best compromise. Quantification of the optimum ranges of several traits by means of simulation models of crop growth is necessary.

This synopsis is based on part of the general discussion in a doctoral thesis entitled 'Physiology of forage maize (Zea mays L.) in relation to its production and quality', Agricultural University, Wageningen, 1983. 252 pp., figs., tables, refs. The major part of this thesis has been published elsewhere. English, Dutch summary.

Available as paper copy (order R009P, $f 40$ including postage) or microfiches (order R009M, $f 22.50$ including postage) at: NARD, clo Pudoc, P.O. Box 4, 6700 AA Wageningen, Netherlands (telex 45015 blhwg hl). 